\title{
MONITORING THE DYNAMIC DEFORMATION OF THE BRIDGE STRUCTURES BY ACCELEROMETERS
}

\author{
Imrich Lipták \\ Department of Surveying, Slovak University of Technology \\ Bratislava, Slovak Republic
}

\begin{abstract}
The paper presents current trends in determining the dynamic deformations of bridge structures through the exploitation of geodetic measurements by accelerometers. The main aim of the paper is to demonstrate the practical application of these measurements on the cycling bridge over the river Morava in Devínska Nová Ves. Possibilities for the processing and analysis of accelerometer measurements by spectral analysis are described. An evaluation of the results is realized based on the modal characteristics from a numerical model designed by the finite element method.
\end{abstract}

Keywords: accelerometer, double integration, deformation, spectral analysis

\section{Introduction}

Bridge structures are usually exposed to the greatest extent by external influences such as weather conditions and loading by some objects. These factors have a significant influence on the behaviour of the structure, which results to deformation of the whole structure or its parts. Changes in structure's deformation have typically a cyclical behaviour that reflects just influences of the surroundings. Therefore, it can be determined rate of the structure's stress and magnitude of the impact of individual factors on the structure.

Nowadays, knowledge of dynamic characteristics of the bridge structure's behaviour is increasingly important. They are caused mainly by wind and moving of objects on the structure (pedestrians, cyclists, vehicles). These affect resonant behaviour of the structure, which result to dynamic deformation of the structure. These are usually described by modal characteristics of the structure's deformation (vibration modes). For safety operation of the structure is necessary to design these deformations by computational modelling and to monitor during the loading tests and 
by long-term monitoring of the structure using suitable methodologies. These data significantly contribute to stability and safe operation of the bridge and can be used to calibration of structural numerical model.

\section{Innovative approaches in identifying dynamic deformation of the bridge structures}

Determining the dynamic deformations of bridge structures can be realized by a number of suitable innovative technologies. Current trends favour the application of automated measurement systems (AMS) for the long-term structural health monitoring of bridges (Kyrinovič et. al., 2011) \& (Wenzel, 2009). An AMS exploits several mutually synchronized technologies. For geodetic monitoring of the dynamic deformations of bridges, AMS mainly uses the following technologies:

- total stations,

- GNSS technology,

- ground radar-interferometry,

- tilt sensors,

- accelerometers.

The exploitation of robotic total stations in structural health monitoring (SHM) is becoming increasingly important. Current technologies implemented in total stations allow the realization of kinematic measurements with a frequency of up to $10 \mathrm{~Hz}$. It is sufficient to determine the significant characteristics of the dynamic deformations of bridges (Psimoulis \& Stiros, 2007). The disadvantage is the uneven time periods of registering measurements (the jitter effect). In this case GNSS technology is mainly used for determining changes in the inclination of bridge pylons and the vibrations of the structure (Roberts, et. al., 2010). This technology can be used in combination with tilt sensors or accelerometers.

This paper describes the methodology for processing the data of the measurements by accelerometers. It describes determining the relative displacement approach from the measured acceleration and the possibilities of determining the modal characteristics of any structural deformations. These possibilities, which use mathematical model, are presented in a case study involving a bridge for pedestrians and cyclists.

\section{Processing and analysing the measurements realized by accelerometers}

The approach for processing the data of the accelerometer measurements is divided into determining the relative displacements and a spectral analysis of the vibrations in the frequency domain. Determining the displacements is usually realized by the numerical computation methods of the Riemann integral. The vibrations generally have a cyclical pattern and can be modelled by spectral analysis methods.

\subsection{Determining relative displacements}

Accelerometers generate an output signal in the form of a time series of the accelerations. Determining relative displacements can be accomplished by several methodologies. The most common method is the double integration of the 
acceleration by a rectangular or trapezoidal rule (Sangbo, 2010). Generally, this problem can be described by the formula

$$
s(t)=s_{0}+v_{0} \times t+\int_{0}^{t}\left(\int_{0}^{t} a(t) d t\right) d t
$$

The selection of the appropriate sample rate has a significant effect on the accuracy of the calculations. In this case it is recommended to provide the measurement with a sample rate at least twice that of the highest significant frequency of the vibration of the structure. Another important factor influencing the accuracy of the integration of the measurements is the implementation of a high-pass filter. By using a suitable filter, the long-period components of the measured signal (e.g., drift) can be eliminated. It is necessary to design such a filter with a minimum frequency and magnitude response. This effect of the filter on the raw measurements can be analysed by a transfer function.

\subsection{Spectral analysis of a dynamic deformation}

In the case of determining bridge vibration modes, spectral analysis methods are used. The most often used is the Fourier transformation. This approach describes a time-dependent signal by harmonic functions, which can be used to signal the transition from the time to the frequency domain. The signal can be expressed continuously or in a discrete form.

In practical applications, a finite number of the data is analysed by the numerical method of the Fourier transformation, known as the discrete Fourier transformation (DFT). Calculation of the DFT can be realized by several algorithms. In the case of the dynamic deformation of bridges, the fast Fourier transformation (FFT) is used most often. The FFT is defined as

$$
X_{x}(f)=\sum_{k=0}^{M} \gamma_{x}(k) w(k) e^{i 2 \pi f k / f_{s}},
$$

where $\gamma_{\mathrm{x}}(k)$ is the autocorrelation function, and $w(k)$ is the spectral window function (Cooley \& Tukey, 1965).

An alternative is the application of the Welch method, which uses the FFT algorithm. In this case, the spectral density of the time series is computed from overlapped segments. These segments are analysed by the FFT method. The results give a smooth periodogram and greater accuracy of the frequencies determined. However, the resolution of the magnitude spectrum is unfortunately lower (Welch, 1967).

A cross-spectral analysis of two time series (signals) is used for the crosscorrelation and the time delay between them. It can be described as a different dynamic response to external effects (wind, pedestrians, cyclists, etc.). The crossspectral density of the two time series can be estimated by the FFT of the crosscorrelation function as

$$
X_{x y}(f)=\sum_{k=0}^{M} \gamma_{x y}(k) w(k) e^{i 2 \pi f k / f_{s}}
$$


where $\gamma_{x y}(k)$ is cross-correlation function, $w(k)$ is spectral window function (Bracewell,1965).

The correlation of two time-synchronized signals at a specific period can be defined by their coherence. The significant frequencies of the signals are determined by the Fisher's periodicity test. The amplitudes and phase shifts of the signals can be estimated by the least squares method.

\section{Case study}

The practical use of the accelerometers and spectral methods of data processing described in the previous chapter were realized on an actual bridge structure. Bridge structures for pedestrians are usually designed as flexible structures with higher values of deformation amplitudes than road and railway bridges. Experimental measurements were realized on a pedestrian and cycling bridge over the river Morava from Devínska Nová Ves (Slovakia) to Schlosshof (Austria). The known modal characteristics of the structure's dynamic deformation are useful for verification of the measured deformations.

\subsection{Devínska Nová Ves - Schlosshof cycling-bridge}

The Devínska Nová Ves - Schlosshof cycling-bridge is constructed on a cycling route between an urban area of Bratislava - Devínska Nová Ves and the Austrian village of Schlosshof (Fig. 1). The bridge spans the Morava River at the $4.31 \mathrm{~km}$ mark. The river forms the border of Slovakia and Austria. The bridge is built on quaternary fluvial and anthropogenic sediments, the thickness of which is from $5 \mathrm{~m}$ to $8 \mathrm{~m}$. It is a steel truss structure consisting of three parts with a full length of $525.0 \mathrm{~m}$. The main steel structure spans the Morava River, and its length is $180.0 \mathrm{~m}$. Inundation bridges with a length of $240.0 \mathrm{~m}$ on the Slovak side and $105.0 \mathrm{~m}$ on the Austrian side were built over both river banks.
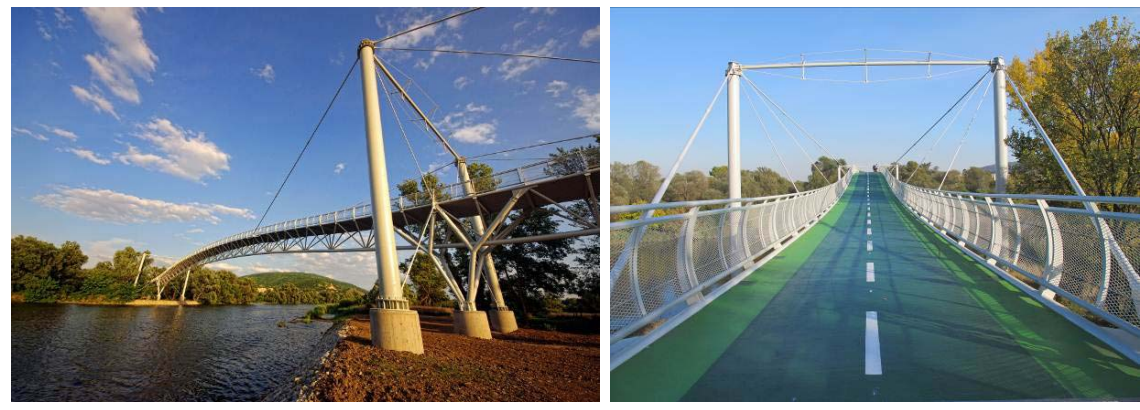

Fig. 1. Cycle-bridge Devínska Nová Ves - Schlosshof

The main steel structure, which is the object of the dynamic deformation monitoring, is a symmetrical cable-stayed steel structure with three sections of 30.00 $+120.0+30.0=180.0$ m length. The loading beam's height is from $2.00 \mathrm{~m}$ to 2.80 $\mathrm{m}$. In the middle section, the loading beam has a ring shape with a $376.35 \mathrm{~m}$ radius. The bridge deck is orthotropic and cable-stayed by loading rods, which are anchored at the tops of four steel pylons with heights of 17.85 m (Agócs \& Vanko, 2010). 


\subsection{Measurement system configuration}

The bridge structure is situated in an area with higher wind intensity. The curved shape of the main steel structure was designed for the clearance of shipping on the Morava River. These factors, as well as pedestrian movements, have a significant influence on any structural deformations. These deformations are characterized by the vertical bending and horizontal torsional oscillation of the bridge deck. For verifying the stability of the bridge structure, an automated measurement system (AMS) was designed. This AMS was designed for the long-term monitoring of the dynamic deformations of the structure (Kopáčik \& Lipták, 2012). Only several of the system's sensors were used for the experimental loading test.

The AMS consists of two HBM B12/200 one-axial accelerometers, which are supported by an HBM Spider 8 A/D converter. The sensors measure acceleration in a vertical direction. They are situated at the centre of the structure and are supported on the deck by loading rods (Figs. $2 \& 3$ ). The Reinhardt WDS $1 \mathrm{MV}$ meteorological station measures the atmospheric conditions in the surroundings of the bridge. The measurements and data registration are managed by a notebook.

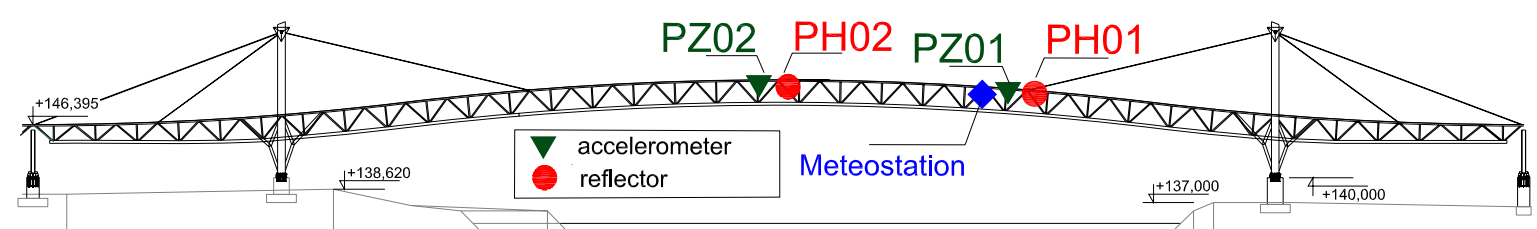

Fig. 2. Configuration of measuring points
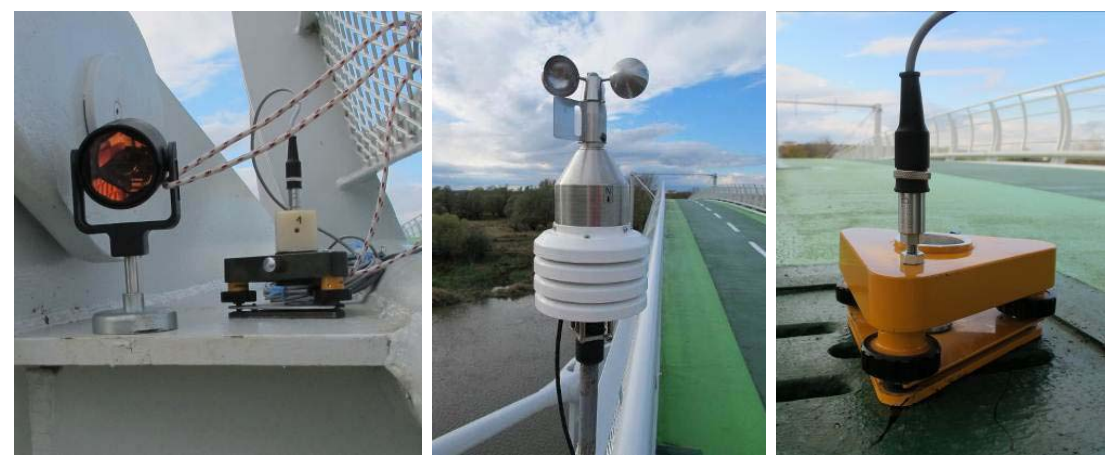

Fig. 3. Stabilization of the sensors on the bridge deck 


\subsection{Experimental measurements}

The measurements were realized by loading several types of structure. The types of loading used were designed based on the FEM (Finite Element Method) model of the structure (Excon, 2010). Table 1 defines each type of the loading of the structure.

Table 1. Loads of the structure

\begin{tabular}{|c|c|}
\hline Epoch & Loading \\
\hline 1 & Without loading \\
\hline 2 & 1 person, walking from Devínska Nová Ves to Schlosshof \\
\hline 3 & 1 person, walking from Schlosshof to Devínska Nová Ves \\
\hline 4 & 1 person, running from Devínska Nová Ves to Schlosshof \\
\hline 5 & 1 person, running from Schlosshof to Devínska Nová Ves \\
\hline 6 & 2 persons, running from Devínska Nová Ves to Schlosshof \\
\hline 7 & 2 persons, running from Schlosshof to Devínska Nová Ves \\
\hline 8 & 2 persons, jumping at the center of the structure \\
\hline
\end{tabular}

During each type of the bridge loading (except for Epoch No. 1), the measurements were realized in three phases (Fig. 4, right). In the first phase, the measurement was started before the loading of the structure. The second phase continued during the loading of the structure according to Table 1 . The last phase of each measurement epoch was realized after the loading of the structure during the damping of the structure. Each epoch lasted approximately 2 minutes. The frequency of the data registration was realized on the level of $200 \mathrm{~Hz}$ due to the requirements for a higher degree of accuracy of the relative displacements and the occurrence of significant frequencies of structural deformations which are higher than $50 \mathrm{~Hz}$.

\subsection{Processing and analysing the data}

Determining the relative displacements by accelerometers was realized by the double integration of the accelerations measured. Accelerometer drift and integration errors were eliminated by a Butterworth high-pass filter with a cut-off frequency at the level of $0.5 \mathrm{~Hz}$. This filter attenuates the magnitude of the spectrum at the frequency of $1 \mathrm{~Hz}$ by $0.64 \%$, which has no significant influence on the determined displacements. The filter was applied before and after the first integration of the velocities. Table 2 contains the maximum values of the vertical displacements for each measurement epoch at both measured points (PZ01 and PZ02).

Table 2 shows the influence of the simulated loading on the vertical displacements. The effect of pedestrians walking has a minimum influence on the vertical displacements. The rapid movement of pedestrians affects the maximum vertical displacements two times more than during the loading by the pedestrian's walking. The harmonic jumping of pedestrians affects the maximum displacements at the level of $3.24 \mathrm{~mm}$ (PZ01) and $8.19 \mathrm{~mm}$ at the centre (PZO2) of the structure. 

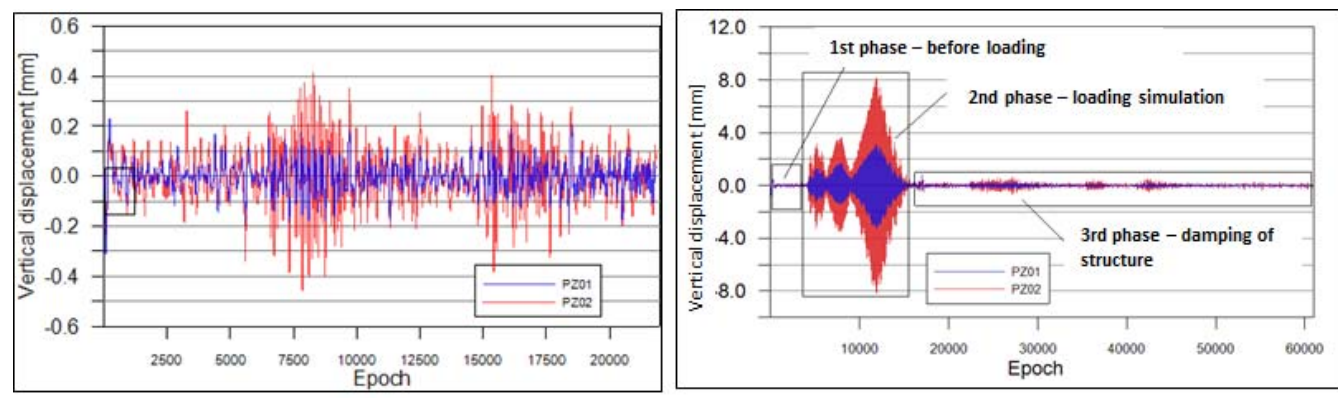

Fig. 4. Vertical displacements during the Epoch Nos. 1 and 8

Table 2. Maximum vertical displacements

\begin{tabular}{|c|c|c|c|c|c|c|c|c|c|}
\hline Epoch & & 1 & 2 & 3 & 4 & 5 & 6 & 7 & 8 \\
\hline $\begin{array}{c}\text { Maximum } \\
\text { displacements } \\
{[\mathrm{mm}]}\end{array}$ & $\begin{array}{l}\text { PZ01 } \\
\text { PZ02 }\end{array}$ & $\begin{array}{l}0.03 \\
0.05\end{array}$ & $\begin{array}{l}0.39 \\
0.29\end{array}$ & $\begin{array}{l}0.35 \\
0.35\end{array}$ & $\begin{array}{l}0.37 \\
0.46\end{array}$ & $\begin{array}{l}0.36 \\
0.47\end{array}$ & $\begin{array}{l}0.67 \\
0.66\end{array}$ & $\begin{array}{l}0.86 \\
0.89\end{array}$ & $\begin{array}{l}3.24 \\
8.19\end{array}$ \\
\hline
\end{tabular}

Before the spectral estimation of the accelerations, each measured time series of the accelerations was filtered by the Butterworth high-pass filter with a cut-off frequency of $0.1 \mathrm{~Hz}$. This filter attenuates the signal amplitudes with a $1 \mathrm{~Hz}$ frequency on the level of $0.2 \%$. This has a minimum influence on the estimation of the expected dominant frequencies of the structural deformations. In this case, it is important to remark that the high-pass filter used does not affect the phase shifts of the signals because it is a zero-phase (symmetrical) filter. Determining the natural frequencies of the structural deformations on each measured point (PZ01 and PZ02) was realized by an auto-spectral analysis using the Welch method with segment lengths of 128 measurements and a $50 \%$ self-overlap.

The purpose of the research topic was a cross-correlation analysis of the time synchronized accelerations measured by both sensors. A cross-spectral analysis of the time series measured by the sensors at the points PZ01 and PZ02 was realized by the Welch method too. The estimation parameters were the same as during the auto-spectral estimation at these points. Fig. 5 illustrates the measured signal and periodogram determined by the auto-spectral and cross-spectral analysis during Epoch No. 1.
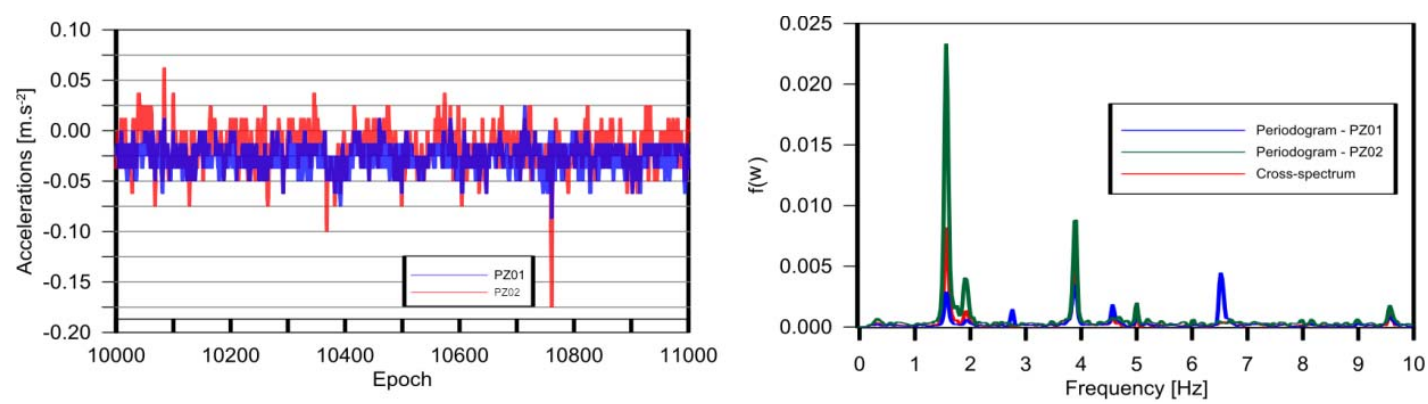

Fig. 5. Measured accelerations and periodogram for Epoch no. 1 
Table 3. Dominant frequencies of structure deformation and phase delays of measured signals at the PZ01 and PZ02

\begin{tabular}{|c|c|c|c|c|c|c|c|c|c|c|}
\hline \multirow{2}{*}{$\begin{array}{l}\text { Vibration } \\
\text { mode }\end{array}$} & \multirow{2}{*}{$\begin{array}{l}\text { Nat. } \\
\text { freq. } \\
{[\mathrm{Hz}]}\end{array}$} & & \multicolumn{8}{|c|}{ Epoch } \\
\hline & & & 1 & 2 & 3 & 4 & 5 & 6 & 7 & 8 \\
\hline 2 & 1.63 & $\begin{array}{c}\text { Frequency } \\
{[\mathrm{Hz}]} \\
\text { Phase }\left[{ }^{\circ}\right] \\
\text { Coherence }\end{array}$ & $\begin{array}{c}1.59 \\
2.9 \\
0.99\end{array}$ & - & - & - & - & - & - & $\begin{array}{c}1.81 \\
1.1 \\
1.00\end{array}$ \\
\hline 22 & 2.15 & $\begin{array}{c}\text { Frequency } \\
{[\mathrm{Hz}]} \\
\text { Phase }\left[^{\circ}\right] \\
\text { Coherence }\end{array}$ & - & $\begin{array}{l}2.15 \\
-5.4 \\
0.79\end{array}$ & $\begin{array}{l}2.00 \\
-0.9 \\
0.77\end{array}$ & - & - & - & - & - \\
\hline 23 & 2.49 & $\begin{array}{c}\text { Frequency } \\
{[\mathrm{Hz}]} \\
\text { Phase }\left[^{\circ}\right] \\
\text { Coherence }\end{array}$ & - & - & - & $\begin{array}{l}2.56 \\
11.6 \\
0.87\end{array}$ & $\begin{array}{l}2.56 \\
19.8 \\
0.72\end{array}$ & $\begin{array}{l}2.56 \\
15.8 \\
0.79\end{array}$ & $\begin{array}{l}2.56 \\
12.4 \\
0.79\end{array}$ & - \\
\hline 44 & 3.76 & $\begin{array}{c}\text { Frequency } \\
{[\mathrm{Hz}]} \\
\text { Phase }\left[^{\circ}\right] \\
\text { Coherence }\end{array}$ & $\begin{array}{l}3.91 \\
-0.2 \\
0.98\end{array}$ & - & - & - & $\begin{array}{l}3.91 \\
-1.1 \\
0.99\end{array}$ & - & $\begin{array}{l}3.91 \\
-2.1 \\
0.99\end{array}$ & $\begin{array}{l}3.91 \\
-1.1 \\
0.99\end{array}$ \\
\hline 59 & 4.69 & $\begin{array}{c}\text { Frequency } \\
{[\mathrm{Hz}]} \\
\text { Phase }\left[{ }^{\circ}\right] \\
\text { Coherence }\end{array}$ & $\begin{array}{c}5.00 \\
178.6 \\
0.88\end{array}$ & - & - & $\begin{array}{c}4.78 \\
175.6 \\
0.93\end{array}$ & - & $\begin{array}{c}4.59 \\
179.5 \\
0.98\end{array}$ & - & $\begin{array}{c}4.59 \\
179.4 \\
0.99\end{array}$ \\
\hline
\end{tabular}

In the next step, the phase shifts of both signals and their coherence were determined. Table 3 contains the natural frequencies of the structural deformations obtained by the FEM model and the corresponding frequencies determined by the cross-spectral analysis at both points. The FEM model contains 5 vibration modes of deformation, which has a significant influence on the structure's dynamic deformation. Table 3 shows the significant influence of pedestrians on the dynamic response of the monitored structure. The dominant frequencies of the deformations estimated during Epoch Nos. 2 and 3 have a good rate of compliance with the $22^{\text {nd }}$ vibration mode of the structure. The estimated frequencies approximately at the $2.10 \mathrm{~Hz}$ level are probably affected by the walking of pedestrians because the frequency of a pedestrian's steps during standard walking has similar values. The phase delay of the signals has a minimum range from $1^{\circ}$ to $5^{\circ}$. Epoch Nos. $4-7$ show the resonant oscillation of the structure affected by running at the $2.50 \mathrm{~Hz}$ level, which corresponds to the frequency of impact of feet on the structure during running. The signals at the $44^{\text {th }}$ vibration mode at the level of $3.91 \mathrm{~Hz}$ have a minimum phase delay in a range from $0^{\circ}$ to $2^{\circ}$. The last modal shape at the frequency level $4.69 \mathrm{~Hz}$ has a higher phase delay between the measured signals. These values are at a level of around half of the period corresponding to this frequency. Epoch No. 8 was realized during the synchronized jumping by two pedestrians at the centre of the structure. The structural oscillation at the frequency level of $1.81 \mathrm{~Hz}$ is affected just by this activity. The estimated frequency is similar to the $2^{\text {nd }}$ natural frequency. According to the results of the FEM model, this natural frequency has a dominant influence on the structure's stability. This assumption was confirmed during the experiment by the low stability of the pedestrians moving on the structure. The signals which correspond to the $2^{\text {nd }}, 44^{\text {th }}$ and $59^{\text {th }}$ vibration modes have a high degree of coherence during all the measurement epochs. The average amplitudes of 
the estimated dominant frequencies are at the levels from $1.0 \times 10^{-3} \mathrm{~m} \cdot \mathrm{s}^{-2}$ to $3.0 \times 10^{-3}$ $\mathrm{m} . \mathrm{s}^{-2}$. The cross-spectral analysis provided an estimate of the significant frequencies of the structure's deformation at the levels higher than $5 \mathrm{~Hz}$, too. These frequencies have only a minimum influence on the stability and dynamic response of the monitored structure.

\section{Conclusions}

The paper presents possibilities for an analysis of structural dynamic deformations by accelerometers. It describes the methodology for the transformation of the measured accelerations to relative displacements. The analysis of the vibration modes and the determining of the oscillation frequencies are realized by spectral analysis. A practical application of the processing and analysis of these data was realized at the cycling bridge at Devínska Nová Ves. The results of the experimental measurements correspond with the FEM model of the main steel structure and can be used for the calibration of this model. The realized measurements show the good use of spectral analysis for measurements of structural deformations, especially dynamic deformations. The results can significantly contribute to the prediction of possible failures of the structure, which can be reflected by anticipated temporal changes in the modal frequencies at the measured points of the structure. These failures can be investigated by other surveying methods such as terrestrial laser scanning.

\section{References}

Agocs, Z. \& Vanko, M. (2010). Devínska Nová Ves - Schlosshof cycling-bridge. Project design - report. Bratislava : INGsteel, a.s. 25 pp. (in Slovak).

Bracewell, R. (1965). Pentagram Notation for Cross Correlation. The Fourier Transform and Its Applications. New York: McGraw-Hill, pp. 46 - 243, 1965.

Cooley, J. W. \& Tukey, J. W. (1965). An algorithm for the machine calculation of complex Fourier series. Mathematic Computation. 19 (90). pp. 297-301.

Excon, Ltd. (2010). Evaluation of the dynamic FEM model of the Devínska Nová Ves - Schlosshof cycling-bridge. 42 pp. (in Slovak).

Kopáčik, A., \& Lipták, I. (2012). Devínska Nová Ves - Schlosshof cycling-bridge. Project design of long-term monitoring. Bratislava : Slovak University of Technology, 2012. 44 pp. (in Slovak).

Kyrinovič, P., Lipták, I., Erdélyi, J. \& Kopáčik, A. (2011). Automated measurement system for long-term monitoring of bridges. Geodetický a kartografický obzor. ISSN 0016-7096, 2011, 57(12), pp. 285-294. (in Slovak).

Psimoulis, P. A. \& Stiros, S. C. (2007). Measurement of deflections and of oscillation frequencies of engineering structures using Robotic Theodolites (RTS). Engineering Structures [online]. 2007. pp. 3312 - 3324, available at: www.elsevier.com/locate/engstruct. ISSN 0141-0296. 
Roberts, G. W., Brown, C. J. \& Ogundipe, O. (2010). Monitoring Bridges by GNSS. Proceedings of FIG Congress "Facing the Challenges - Building the Capacity", Sydney, Australia, 11-16 April 2010. 11 pp.

Sangbo, H. (2010). Measuring displacement signal with an accelerometer. Journal of Mechanical Science and Technology. 24(6). ISSN 1976-3824. pp. 1329-1335.

Welch, P. D. (1967). The Use of Fast Fourier Transform for the Estimation of Power Spectra: A Method Based on Time Averaging Over Short, Modified Periodograms. IEEE Transactions on Audio Electroacoustics, pp. 70-73.

Wenzel, H. (2009). Health Monitoring of Bridges. John Wiley \& Sons, Ltd. 2009. 643 pp. ISBN 978-0-470-03173-5.

\section{Authors:}

Imrich Lipták, Ing.,Imrich.liptak@stuba.sk

Department of Surveying, Faculty of Civil Engineering,

Slovak University of Technology, Bratislava, Slovak Republic 